\title{
Measuring basal soil respiration across Europe: Do incubation temperature and incubation period matter?
}

\author{
R.E. Creamer ${ }^{\mathrm{a}, *}$, R.P.O. Schulte ${ }^{\mathrm{a}}$, D. Stone ${ }^{\mathrm{a}}$, A. Gal ${ }^{\mathrm{b}}$, P.H. $\mathrm{Krogh}^{\mathrm{c}}$, G. Lo Papa ${ }^{\mathrm{d}}$, \\ P.J. Murray ${ }^{\mathrm{e}}$, G. Pérès ${ }^{\mathrm{f}}$, B. Foerster ${ }^{\mathrm{g}}$, M. Rutgers ${ }^{\mathrm{h}}$, J.P. Sousa ${ }^{\mathrm{i}}$, A. Winding ${ }^{\mathrm{j}}$ \\ a Teagasc, Environment, Soils and Land Use Research Department, Johnstown Castle, Ireland \\ b Szent Istvan University, Gödöllö, Hungary \\ c Aarhus University, Department of Bioscience, Denmark \\ d Dipartimento dei Sistemi Agro-Ambientali, University of Palermo, Italy \\ e Rothamsted Research, North Wyke, Okehampton, Devon, United Kingdom \\ ${ }^{\mathrm{f}}$ UMR 6353 EcoBio CNRS-University of Rennes 1, France \\ ${ }^{g}$ ECT Oekotoxikologie GmbH, Germany \\ h National Institute for Public Health and the Environment, The Netherlands \\ i IMAR-CMA, Department of Life Sciences, University of Coimbra, Portugal \\ ${ }^{\mathrm{j}}$ Aarhus University, Department of Environmental Science, Denmark
}

\section{A R T I C L E I N F O}

\section{Article history:}

Received 21 March 2012

Received in revised form 15 August 2013

Accepted 19 August 2013

\section{Keywords:}

Basal respiration

Monitoring

Standardisation

Pre-incubation temperatures and experimental incubation temperatures Soil

\begin{abstract}
A B S T R A C T
The European Commission recognises the essential role of soil biology in soil functioning and delivery of ecosystem services, but information is currently lacking evaluate of how these vary across soil and land-use types at a European scale. This study evaluated the measurement of the initial rate of soil basal respiration (BR) as a potential biological indicator of ecosystem service provision. The purpose of this study was to test ISO 16072:2002 (Soil Quality: Laboratory methods for the determining of microbial soil respiration). In the literature a range of pre-incubation temperatures (pre-inc) and experimental incubation temperatures (exp-inc) have been applied when using the ISO method for the establishment of basal respiration. This study evaluated whether the range of temperatures applied during pre- and exp- incubation had a significant effect on the rate of respiration determined when following the protocol established in ISO 16072:2002. The evaluation was carried out on a pedo-climatic gradient spanning ten countries across Europe and covering four biogeographical regions. Three sites were sampled in each country providing a range of soil and land-use parameters. Our results suggest that experimental incubation temperatures of $20^{\circ} \mathrm{C}$ or above should be used in the application of the methodology ISO $16072: 2002$ (incubation at $15^{\circ} \mathrm{C}$ resulted in erratic variation between replicates). However, pre-incubation temperature did not affect the soil basal respiration rate, when following the standard recommendations. The time interval with the best prediction of the initial rate of basal respiration was $6 \mathrm{~h}$.
\end{abstract}

(C) 2013 Elsevier Ltd. All rights reserved.

\section{Introduction}

The development of biological indicators to assess changes in soil quality is an increasingly important research area. It is now accepted that soil biology is the driving force behind many soils processes (Francaviglia, 2008) and supports the delivery of soil and soil ecosystem functions such as nutrient transformations, water purification and carbon sequestration.

Currently, there is a plethora of data available on biological indicators. This information has been collected using a wide range

\footnotetext{
* Corresponding author. Tel.: +353 539171266.

E-mail address: rachel.creamer@teagasc.ie (R.E. Creamer).
}

of methods, each applied in specific environmental situations, complicating the meaningful comparison of data. The example addressed in this paper is the assessment of microbial basal respiration, frequently used to quantify changes in the activity of the soil microbial community (Winding et al., 2005; Bispo et al., 2009).

Soil basal respiration is defined as the steady rate of respiration in soil, which originates from the mineralisation of organic matter (Pell et al., 2006), and is estimated either on the basis of $\mathrm{CO}_{2}$ evolution or $\mathrm{O}_{2}$ uptake (Dilly and Zyakun, 2008). The measurement of soil basal respiration has been applied across a variety of research studies and both soil microbial respiration and the mineralisation of organic matter are commonly accepted as a key indicator for measuring changes to soil quality. Two stages of respiration response are quantified under the heading soil basal respiration 
Table 1

Evaluation of literature on the measurement of basal respiration rate for experimental- and pre-incubation periods and temperatures.

\begin{tabular}{|c|c|c|c|c|c|}
\hline Authors & Year & Exp-inc sampling & Exp-inc temperature & Pre-inc period & Pre-inc temperature \\
\hline Cĕrnohlávková et al. & 2009 & $24 \mathrm{~h}$ & $20^{\circ} \mathrm{C}$ & 3 days & $20^{\circ}-22^{\circ} \mathrm{C}$ \\
\hline Uzun and Uyanoz & 2011 & $24 \mathrm{~h}$ & $25^{\circ} \mathrm{C}$ & Not defined & \\
\hline Hofman et al. & 2004 & $24 \mathrm{~h}$ & Not defined & 7 days & $22^{\circ} \mathrm{C}$ \\
\hline Ritz and Wheatley & 1989 & & $25^{\circ} \mathrm{C}$ & Not defined & \\
\hline Grayston et al. & 2001 & $24 \mathrm{~h}$ & $15^{\circ}$ and/or $30^{\circ} \mathrm{C}$ & Not defined & \\
\hline Maassen \& Wirth & 2004 & $8 \mathrm{~h}$ & $20^{\circ} \mathrm{C}$ & 2 days & $20^{\circ} \mathrm{C}$ \\
\hline Rousk et al. & 2009 & $22-24 \mathrm{~h}$ & $22^{\circ} \mathrm{C}$ & 1 week & $22^{\circ} \mathrm{C}$ \\
\hline Bundy et al. & 2004 & $6 \mathrm{~h}$ & Not defined & Not defined & \\
\hline Mulder et al. & 2005 & 5 weeks & $20^{\circ} \mathrm{C}$ & 4 weeks & $12^{\circ} \mathrm{C}$ \\
\hline Vanhala et al. & 2005 & $6 \mathrm{~h}$ & $14^{\circ} \mathrm{C}$ & 7 days & $14^{\circ} \mathrm{C}$ \\
\hline Gömöryová & 2011 & $24 \mathrm{~h}$ & $22^{\circ} \mathrm{C}$ & Not defined & \\
\hline Bárcenas-Moreno & 2011 & 4 days & $25^{\circ} \mathrm{C}$ & Not defined & \\
\hline Fernandes & 2005 & 10 days & Not defined & 5 days & Not defined \\
\hline Fließbach et al. & 2007 & $72 \mathrm{~h}$ & Not defined & 7 days & $22{ }^{\circ} \mathrm{C}$ \\
\hline
\end{tabular}

within the literature: 1) an initial rate of respiration and 2) the growth response. This paper will only consider the initial response rate of basal respiration and its response to a range of incubation temperatures.

Anderson and Domsch (1977) emphasise the need for identical conditions of soil incubation, to be able to compare intrinsic differences across soils. However, a wide range of experimental incubation conditions were found within the literature; with ranges in experimental incubation temperature from $14^{\circ}$ to $25^{\circ} \mathrm{C}$, and incubation periods from a minimum of $6 \mathrm{~h}$ up to a maximum of 6 weeks (Table 1 ).

The adoption of soil biological measurements as broad-scale monitoring indicators requires consistency and accuracy within a method across a range of environmental conditions such as soil type; vegetation type; and climate (Creamer et al., 2009). In order to adopt soil respiration as a universal tool for monitoring changes in soil quality it is essential to validate the precision of the international standard method (ISO 16072:2002 Soil Quality: Laboratory methods for the determining of microbial soil respiration). This study aimed to assess the implication of a range of experimentalincubation and pre-incubation temperatures on a range of soils representing a pedo-climatic gradient across Europe (Fig. 1). A pedo-climatic gradient represents a spectrum of the complex interactions between climate, geology and vegetation across Europe, ranging from dry, shallow soils in the Mediterranean to deeper, poorly drained soils under Boreal conditions.

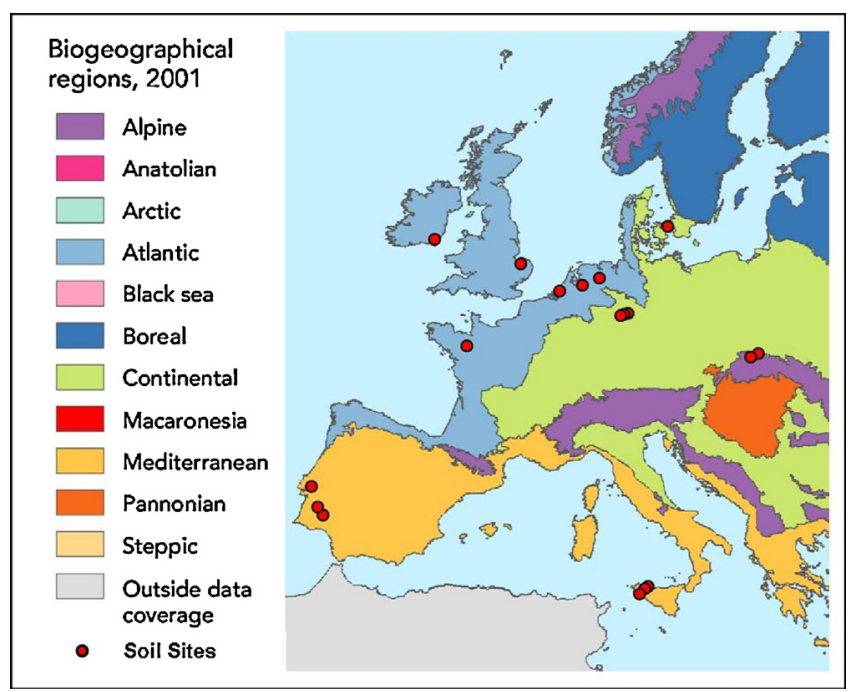

Fig. 1. Map depicting the distribution of sites across Europe, throughout the biogeographical regions (European Environment Agency, 2002).

\subsection{Experimental incubation (exp-inc) and pre-incubation (pre-inc) temperature ranges}

The International Standard ISO 16072:2002 was promoted within a recent large scale pan-European project to evaluate indicators for monitoring changes in soil quality (ENVASSO) (Bispo et al. 2009) as the accepted methodology for the measurement of soil basal respiration. The standard allows for the measurement of the initial rate of soil basal respiration at a range of temperatures (during the exp-inc and pre-inc periods of the assay).

Temperature is held to a controlled heat during the method (the exp-inc temperature), as temperature is considered to significantly affect the rates at which respiration takes place (Winding et al., 2005). The ISO 16072:2002 recommends a range of exp-inc temperatures between $20^{\circ}$ to $30^{\circ} \mathrm{C}$, but states that other temperatures may be applied. The extent to which any exp-inc temperature effects are expressed or masked in sample sets containing soils of highly varied origin is not clear. We therefore set out to evaluate three exp-inc temperatures of $15^{\circ}, 20^{\circ}$ and $25^{\circ} \mathrm{C}$ on a pedo-climatic gradient of soils, reflecting the temperature range found in the literature.

A pre-inc temperature is applied to settle and standardise the soil microbial community following disturbance of sampling and sieving, allowing the initial carbon flush to diminish (Bloem et al., 2006). Pre-inc temperatures and periods of duration have been defined by a group of experts across Europe (Table 2). These pre-inc temperatures provide a range of mesophilic temperature conditions which reflect different climatic zones. The Q10 established for each temperature by time period, results in the same incubation conditions having being applied to all soils when the endpoint is reached.

\subsection{Length of experimental-incubation period}

With the aim of achieving a high-throughput of samples, measurements of basal respiration rates are commonly derived from a single time point $\mathrm{CO}_{2}$ measurement. This is beneficial in national or European monitoring systems where the labour intensity of a method is an important consideration. The timing of this one-off measurement of $\mathrm{CO}_{2}$ concentration varies, with many

Table 2

Recommended soil pre-incubation periods prior to measurement of soil basal respiration (Jones et al., 2008).

\begin{tabular}{ll}
\hline Period of pre-incubation & Temperature of pre-incubation \\
\hline 2 to 3 days & $25^{\circ}$ to $28^{\circ} \mathrm{C}$ \\
1 week & $20^{\circ} \mathrm{C}$ \\
2 weeks & $15^{\circ} \mathrm{C}$ \\
4 weeks & $10^{\circ} \mathrm{C}$ \\
\hline
\end{tabular}




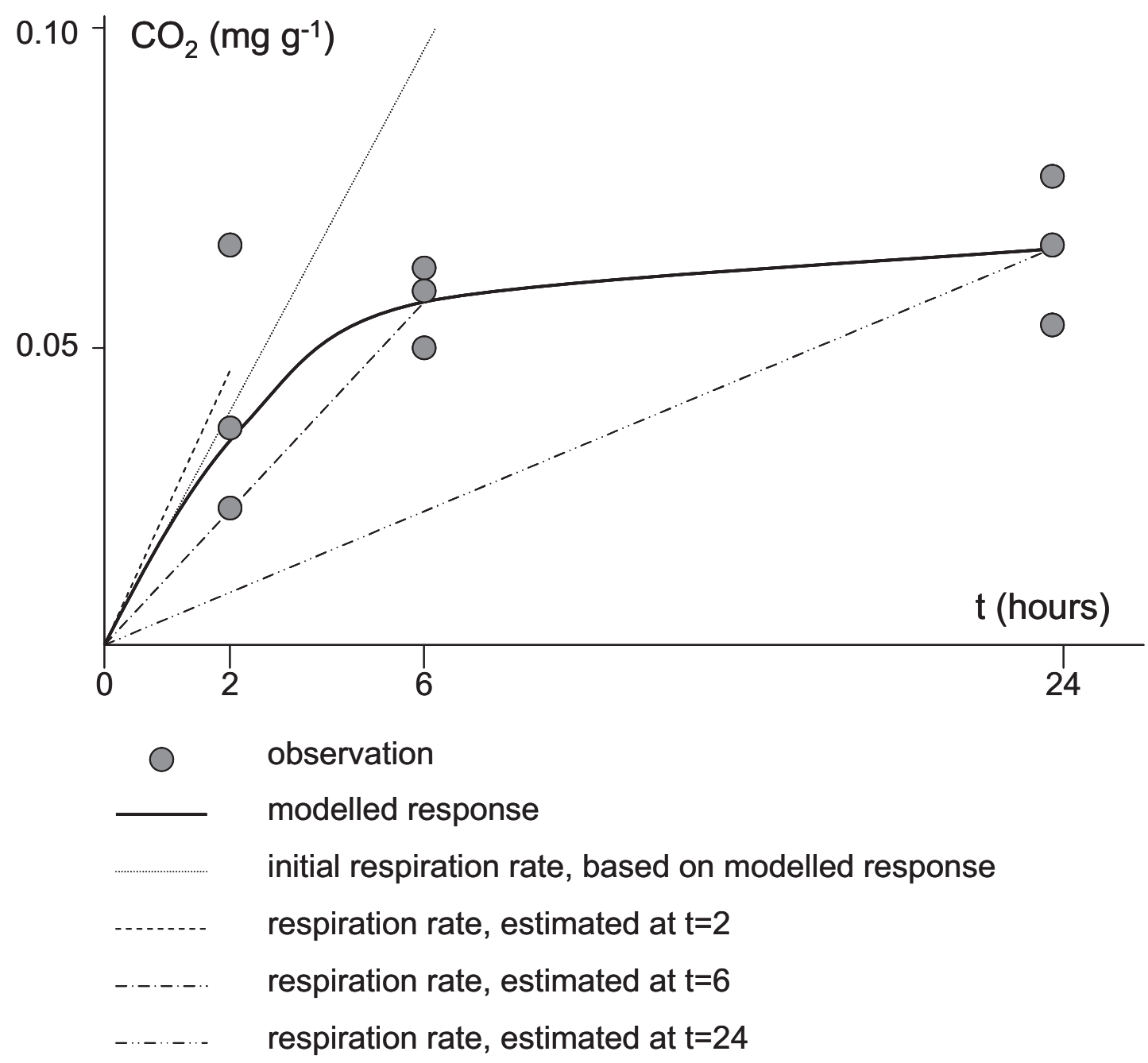


to estimates of the average respiration rates, based on individual measurements of respiration at times $t=2,6$ and 24 (the three dashed lines).

studies reporting $24 \mathrm{~h}$ of incubation (e.g. Grayston et al., 2001; Hofman et al., 2004; Uzun and Uyanoz, 2011), while incubation times as short as $6 \mathrm{~h}$ have been reported (Bundy et al., 2004; Vanhala et al., 2005). ISO 16072:2002 indicates that one reading after $20-24 \mathrm{~h}$ is sufficient (in addition to the initial T0 reading). However, a single measurement of $\mathrm{CO}_{2}$ concentration assumes a linear increase in $\mathrm{CO}_{2}$ concentration over time, rendering timing of gas sampling inconsequential within the first $24 \mathrm{~h}$; this is shown by the variety of sampling periods indicated in Table 1 . But non-linear increases in $\mathrm{CO}_{2}$ concentration over time have been reported, with $\mathrm{CO}_{2}$ concentrations either accelerating or approaching a maximum value within $24 \mathrm{~h}$, (e.g. Ritz et al., 2006). Therefore in an ideal scenario $\mathrm{CO}_{2}$ concentrations should be measured multiple times during the exp-inc period to facilitate assessment of the linearity of the response over time. This is exemplified in Fig. 2: in this (hypothetical) scenario, $\mathrm{CO}_{2}$ concentrations of each of the three hypothetical replicates were measured three times during the incubation period, i.e. at $t=2,6$ and $24 \mathrm{~h}$ (dots on the graph). These longitudinal measurements allow the (nonlinear) increase in $\mathrm{CO}_{2}$ concentration to be fitted by an appropriate model (solid line), from which the initial slope of the model, i.e. the initial respiration rate, can be established (dotted line). If only a single observation is applied after one given length of time, this can lead to both underestimation and overestimation of the initial respiration rate, for two different reasons: in this example (Fig. 2), a single reading of the average respiration rate at $t=24$ (dash-dot-dotted line) will underestimate the initial respiration rate at $t=0$, due to the non-linearity of the increase in $\mathrm{CO}_{2}$ concentration. In addition, under or overestimation of the initial respiration rate may arise from random errors in the measurements at one single point in time. In the example of Fig. 2, the average respiration rate at $t=2$ (dashed line) overestimates the initial respiration rate, as a result of the large random variation in $\mathrm{CO}_{2}$ concentration between replicates for this specific time interval.

As with variations in exp-inc temperature, the potential range of exp-inc periods creates problems when comparing published studies. Therefore, in order to present a detailed evaluation of ISO 16072:2002, we investigated the accuracy of using an average respiration rate, based on one single reading at the end of the exp-inc period, to calculate the initial rate of basal respiration, in comparison to the initial respiration rate derived from multiple readings throughout the exp-inc period.

\subsection{Objectives}

The overall objectives of this study were to evaluate the methodological measurement of the initial rate of basal soil respiration, 
Table 3

Climatic and land-use properties of sites.

\begin{tabular}{|c|c|c|c|}
\hline Country & Land-use & $\begin{array}{l}\text { Average soil } \\
\text { temperature } \\
\left({ }^{\circ} \mathrm{C}\right)\end{array}$ & $\begin{array}{l}\text { Average } \\
\text { temperature of } \\
\text { the growing } \\
\text { season }\left({ }^{\circ} \mathrm{C}\right)\end{array}$ \\
\hline Ireland & Grassland & 11.12 & 10.67 \\
\hline Ireland & Tillage & 11.12 & 10.67 \\
\hline Ireland & Forest & 11.12 & 10.67 \\
\hline France & Forest & 11.49 & 12.04 \\
\hline France & Tillage & 11.49 & 12.04 \\
\hline France & Grassland & 11.49 & 12.04 \\
\hline Germany & Tillage & 11.6 & 13.16 \\
\hline Germany & Grassland & 11.6 & 13.16 \\
\hline Germany & Fallow & 11.6 & 13.18 \\
\hline Denmark & Arable & 8.66 & 12.20 \\
\hline Denmark & Arable & 8.66 & 12.20 \\
\hline Denmark & Arable & 8.66 & 12.20 \\
\hline Hungary & Grassland & No data & 15.25 \\
\hline Hungary & Tillage & No data & 15.25 \\
\hline Hungary & Forest & No data & 12.50 \\
\hline UK & Grassland & 9.90 & 12.10 \\
\hline UK & Tillage & 9.90 & 12.10 \\
\hline UK & Fallow - long-term & 9.90 & 12.10 \\
\hline Portugal & Grassland & No data & $23 \pm 3$ \\
\hline Portugal & Fallow & No data & $23 \pm 3$ \\
\hline Portugal & Fallow & No data & $23 \pm 3$ \\
\hline Italy & Tillage & No data & 17.19 \\
\hline Italy & Grassland & No data & 14.79 \\
\hline Italy & Forest & No data & 14.79 \\
\hline Greenland & Dwarf shrub heath & 2.08 & 7.18 \\
\hline Greenland & Dwarf shrub heath & 2.08 & 7.18 \\
\hline Greenland & Dwarf shrub heath & 2.08 & 7.18 \\
\hline Netherlands & Tillage & 10.70 & 12.60 \\
\hline Netherlands & Forest & 10.70 & 12.60 \\
\hline Netherlands & Tillage - Organic & 10.40 & 12.46 \\
\hline
\end{tabular}

using a range of soils sampled from a pedo-climatic gradient across Europe. The key questions to be answered were;

- Does experimental-incubation (exp-inc) temperature affect the response of the initial respiration rate for basal respiration and if so, what exp-inc temperature gives the most consistent results?

- Does pre-incubation (pre-inc) temperature affect the response of the initial respiration rate for basal respiration and if so, what pre-inc temperature gives the most consistent results?

- What is the optimum length of exp-inc period, if only one gas measurement can be facilitated?

\section{Material and methods}

\subsection{Site selection}

Samples were collected from ten countries to achieve a range of climatic zones (Mediterranean, Continental, Atlantic and Boreal) (Fig. 1). Within each country three sites of contrasting land-use (i.e. arable, grass and woodland) were sampled to provide a spectrum of soils for analyses. The sampling sites were prescribed to provide a range of soil physical and chemical characteristics and to ensure a range and contrast in the soil microbiological properties being considered in this study. Each country sampled a clay loam, loam and sandy loam soil. Only one sample per site was taken, as this was a method comparison exercise and we merely required a spectrum of soil properties under a range of land-uses. Samples were taken over a two-week period in June 2009. Data relating to the site location and land-use was collected and climatic data obtained from the nearest weather station (Table 3).

\subsection{Sample collection and preparation}

A protocol was developed for sampling, following ISO 103816:1993a. Sites were sampled to a depth of $10 \mathrm{~cm}$, with the removal of surface vegetation. Soil samples were sieved fresh to $<2 \mathrm{~mm}$ and kept in a cold room $\left(<4^{\circ} \mathrm{C}\right)$. All samples were and posted within ten days of sampling, postage packages were kept cool (approx. $<4{ }^{\circ} \mathrm{C}$ ) during transit by the insertion of coolpacks. On arrival samples were stored at $<4{ }^{\circ} \mathrm{C}$ in the dark during the process of preparation for the measurement of basal respiration. Sample storage did not exceed four weeks from sampling date.

Sub-samples were taken during the storage period to measure water holding capacity and moisture content. Water-holding capacity of sieved soil was measured using a Haines-funnel system, where $100 \mathrm{ml}$ of water was added to $50 \mathrm{~g}$ of fresh soil in a funnel for $30 \mathrm{~min}$. Excess water was collected from the funnel system and its volume measured (Jenkinson and Powlson, 1976). Moisture content was determined using the Gravimetric method as laid out in the Soil Quality ISO Section 3.1 (ISO 11465:1993b), with the modification of using only $5 \mathrm{~g}$ soil per sample. In accordance with ISO 16072:2002, moisture contents of soil samples were adjusted to a water holding capacity of $40-60 \%$.

Following coning and quartering a $200 \mathrm{~g}$ sub-sample of soil was incubated in a plastic bag with a wet wick to maintain constant moisture content. Soils were pre-incubated in the dark at a range of temperatures and corresponding time periods following the recommendation of Jones et al. (2008), (Table 2).

\subsection{Determination of basal respiration}

Basal respiration was determined in serum bottles following ISO 16072:2002 - Section 5.5. Samples were randomly allocated numbered bottles and from that point on were blind sampled (i.e. no knowledge of sample origin). Three replicates of each soil sample were processed. To pressurise the system we added $21 \mathrm{~cm}^{3}$ of laboratory air and the sampling syringe was pumped twice in the laboratory atmosphere before injection. After every three bottles pressurised, an ambient air sample from the laboratory was taken and analysed to measure background conditions. Gas samples were taken from the bottle headspace at regular intervals. Samples were inserted into pre-evacuated vials, the syringe was pumped twice in the headspace before the $7 \mathrm{~cm}^{3}$ samples were taken. Gas vials were analysed using a Varian CP-3800 GC fitted with a packed column and the carrier gas was argon. $\mathrm{CO}_{2}$ concentration was calculated for each sample replicate using Star Chromatography Workstation (2004). Calculation of the rate of $\mathrm{CO}_{2}$ formation was determined using the method provided by ISO 16072:2002.

To answer the objectives laid out in the introduction, two experiments were conducted, using three replicate sub-samples of the soils from each site for each incubation temperature;

1) An Exp-inc experiment which applied a standardised pre-inc temperature of $20^{\circ} \mathrm{C}$ for a period of 7 days. Soils were subsequently incubated at $15^{\circ}, 20^{\circ}$ and $25^{\circ} \mathrm{C}$ for a period of $24 \mathrm{~h}$. Gas samples were taken at time intervals 0,6 and $24 \mathrm{~h}$. This experiment did not include samples collected from Greenland.

2) A Pre-inc experiment, which assessed a range of pre-inc temperatures (at $10^{\circ}, 15^{\circ}, 20^{\circ}$ or $25^{\circ} \mathrm{C}$, at the corresponding time periods - see Table 2 ). Soils were experimentally incubated at a standardised temperature of $20^{\circ} \mathrm{C}$, following gas sampling $\mathrm{T} 0$, for a period of $24 \mathrm{~h}$. Gas samples were taken at time intervals 0 , 2,6 and $24 \mathrm{~h}$. 


\subsection{Data analysis}

Cumulative $\mathrm{CO}_{2}$ production at each time period was calculated by subtracting the ambient $\mathrm{CO}_{2}$ concentrations at time $=0$ from the corresponding $\mathrm{CO}_{2}$ concentrations measured at time intervals 2, 6 and $24 \mathrm{~h}$.

We evaluated three descriptive models to describe the observed increases in $\mathrm{CO}_{2}$ concentration over time and to derive the initial respiration rate; these were the non-rectangular hyperbola (Eq. (1)), the Michaelis-Menten equation (Eq. (2)) and the common negative exponential curve (Eq. (3)). These models were selected as they each quantify biological scenarios where a rate variable (in our case the increase in $\mathrm{CO}_{2}$-concentrations) changes over time before "settling" at a constant rate.

\subsubsection{Non-rectangular hyperbola}

Non-rectangular hyperbola, which is a complex but versatile three-parameter saturation curve that can be denoted as:

$\mathrm{CO}_{2}=\frac{r_{0} \cdot t+\mathrm{CO}_{2, \max }-\sqrt{\left(r_{0} \cdot t+\mathrm{CO}_{2, \max }\right)^{2}-4 \cdot q \cdot r_{0} \cdot t \cdot \mathrm{CO}_{2, \max }}}{2 q}$

where $\mathrm{CO}_{2}\left(\mathrm{mg} \mathrm{CO} \mathrm{CO}^{-1}\right.$ soil) is the quantity of $\mathrm{CO}_{2}$ produced, $t(\mathrm{~h})$ is the time at which $\mathrm{CO}_{2}$ concentration was measured, $\mathrm{CO}_{2, \max }(\mathrm{mg}$ $\mathrm{CO}_{2} \mathrm{~g}^{-1}$ soil) is the asymptotic maximum quantity of $\mathrm{CO}_{2}$ produced, $r_{0}\left(\mathrm{mg} \mathrm{CO} \mathrm{Cg}^{-1}\right.$ soil $\left.^{-1}\right)$ is the initial respiration rate, and $q$ (no dimensions) is a parameter describing the "acuteness" of the curve.

\subsubsection{Michaelis-Menten equation}

Michaelis-Menten equation, which is a simple two-parameter saturation curve commonly used to describe chemical and biological processes; this equation can be written as:

$\mathrm{CO}_{2}=\mathrm{CO}_{2, \max } \cdot \frac{t}{t+K}$

In which $\mathrm{CO}_{2}, \mathrm{CO}_{2, \max }$ and $t$ are as described above, and $K(\mathrm{~h})$ is the half-response time, i.e. the time at which the quantity of $\mathrm{CO}_{2}$ concentration equates to half of the (asymptotic) $\mathrm{CO}_{2 \text {,max }}$. The Michaelis-Menten curve approaches linearity for $K \rightarrow \infty$; as such it is capable of fitting linear data.

\subsubsection{Negative exponential equation}

For curves originating from the origin, the common negative exponential curve can be denoted as the following two-parameter curve:

$\mathrm{CO}_{2}=\mathrm{CO}_{2, \max } \cdot\left(1-e^{\mathrm{c} . \mathrm{t}}\right)$

In which $\mathrm{CO}_{2}, \mathrm{CO}_{2, \max }$ and $t$ are as described above, and $c(\mathrm{~h})$ is a parameter, usually taking a negative value, describing the shape of the curve.

We fitted each of these models to each of the soils $\times$ treatments, by minimising the residual sum of squares between observations and model predictions.

\section{Results}

\subsection{Model evaluation}

A wide variety of responses of $\mathrm{CO}_{2}$ concentration to exp-inc temperature and length of exp-inc were observed, both in terms of the magnitude of the responses and their temporal patterns. Fig. 3 shows an example of a typical response (Hungary, grassland site, loam soil, $\mathrm{pH} 8.3$ ) of observed $\mathrm{CO}_{2}$ concentration (diamonds), measured at $t=6$ and $t=24$, for the three exp-inc temperatures. Other sites followed similar patterns: in general, higher exp-inc
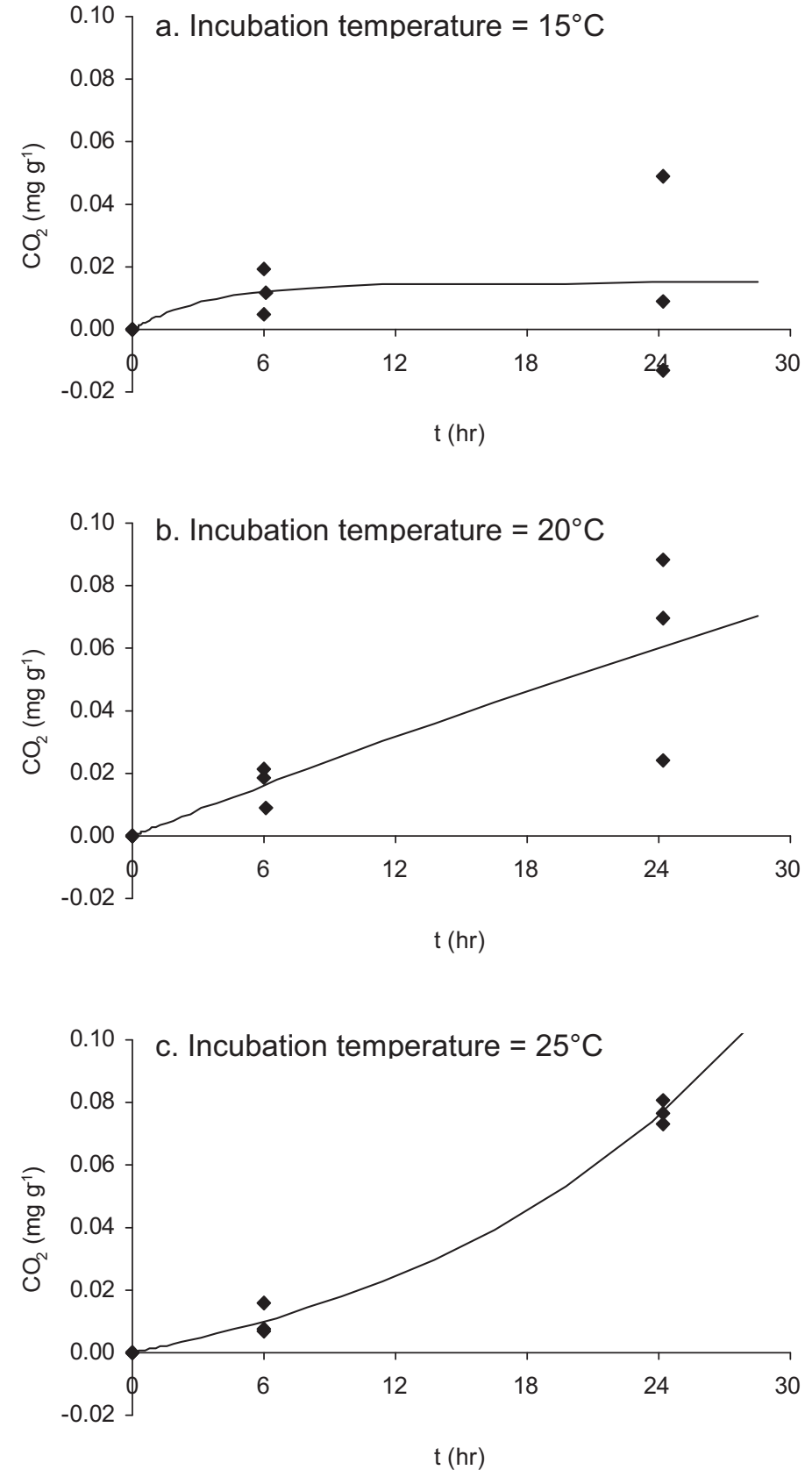

Fig. 3. An example (Hungary, grassland site, loam soil) of a typical response of $\mathrm{CO}_{2}$ during the incubation period, for the three contrasting experimental incubation temperatures of a) $15^{\circ} \mathrm{C}$; b) $20^{\circ} \mathrm{C}$ and c) $25^{\circ} \mathrm{C}$. Solid line shows best fit using the negative exponential model.

temperatures resulted in a) lower coefficients of variance on individual sampling occasions and b) a change in response type from asymptotic to linear and even exponential.

Of the three models, the non-rectangular hyperbola tended to overfit the data, as a result of its high number of free parameters. This means that a "perfect" model fit was obtained for a wide range of parameter combinations, rendering the optimised parameter values meaningless. The Michaelis-Menten equation satisfactorily described the asymptotic and linear curves, and, having only two parameters, resulted in exclusive best estimates of the parameters. However, this model failed to adequately describe the scenarios in which $\mathrm{CO}_{2}$ concentration increases exponentially; in these scenarios the model converged to linearity, resulting in overestimation of $r_{0}$. By contrast, the negative exponential model 
Table 4

\begin{tabular}{|c|c|c|c|}
\hline \multirow[t]{2}{*}{ Incubation temperature } & \multicolumn{2}{|c|}{ Average coefficient of determination } & \multirow{2}{*}{$\begin{array}{l}\% \text { of samples in } \\
\text { which } M M>N E\end{array}$} \\
\hline & Michaelis-Menten (MM) & Negative exponential (NE) & \\
\hline $15^{\circ} \mathrm{C}$ & 0.239 & 0.224 & $25 \%$ \\
\hline $20^{\circ} \mathrm{C}$ & 0.679 & 0.686 & $0 \%$ \\
\hline $25^{\circ} \mathrm{C}$ & 0.789 & 0.817 & $0 \%$ \\
\hline
\end{tabular}

satisfactorily described all scenarios, i.e. asymptotic, linear and exponential curves; this is exemplified by the model fits in Fig. 3 and by the comparison of the coefficients of determination between the Michaelis-Menten equation and the negative exponential curve in Table 4.

Differentiation of Equation 3 and subsequent substitution of 0 for $t$ in the derivative shows that, using this equation, the initial respiration rate $\left(r_{0}\right)$ is defined by $-c \cdot \mathrm{CO}_{2, \max }$. Over time, this equation approaches the asymptotic maximum value of $\mathrm{CO}_{2 \text {,max }}$; the pace of this approach is determined by parameter $c$, with more negative values for $c$ resulting in faster approaches. The negative exponential curve approaches linearity for $c \rightarrow 0$; as such it is capable of fitting linear data. Moreover, the same equation can be used to describe alternative scenarios in which $\mathrm{CO}_{2}$ concentration accelerates over time, i.e. to describe an exponential increase. In these scenarios, parameter $c$ takes a positive value; this results in artificially negative asymptotic values for $\mathrm{CO}_{2, \max }$; however, it can be shown that in such cases, $r_{0}$ is still accurately defined by the product of $-c \cdot \mathrm{CO}_{2, \max }$. Therefore, this model was adopted and employed for further data analysis.

\subsection{Effect of exp-inc temperature and pre-inc temperature on respiration response over time}

Incubation temperature had two effects on the response of $\mathrm{CO}_{2}$ concentration over time:

1. The first effect of exp-inc was that at lower exp-inc temperatures, variation within replicates was negatively affected. At $15^{\circ} \mathrm{C}$ expinc temperature, there was more random variation between replicates (e.g. Fig. 3). In addition, at this temperature occasional erratic responses were observed, where $\mathrm{CO}_{2}$ concentration at $t=24$ was significantly lower than at $t=6$, or on occasions lower than at $t=0$. At exp-inc temperatures of $20^{\circ} \mathrm{C}$ and $25^{\circ} \mathrm{C}$, both the random variation between replicates and the incidence of erratic responses were progressively reduced. As a result the coefficient of determination for the negative exponential model increased with higher exp-inc temperatures. Fig. 4 visualises the cumulative frequency distribution of this coefficient of determination for each of the exp-inc temperatures; it shows that at $15^{\circ} \mathrm{C}$ (dotted line) the coefficient was lower than 0.70 for all samples and lower than 0.50 in most cases. Exp-inc temperatures of $20^{\circ} \mathrm{C}$ (dashed line) and $25^{\circ} \mathrm{C}$ (solid line) resulted in higher coefficients of determination, mostly in excess of 0.50 and 0.80 , respectively. Contrastingly, the pre-inc temperature did not have any effect on random variation between replicates, nor on the incidence of erratic responses. Fig. 5 shows that the coefficient of determination exceeded 0.80 for more than $75 \%$ of the samples in the pre-inc experiment, irrespective of pre-inc temperature.

2. The second effect of exp-inc temperature was that, in general, it affected the shape of the response. An exp-inc temperature of $15^{\circ} \mathrm{C}$ resulted in mostly asymptotic responses, while linear and exponential responses were progressively more frequently observed at exp-inc temperatures of $20^{\circ} \mathrm{C}$ and $25^{\circ} \mathrm{C}$ (see Fig. 3 for a typical example). We have visualised this in Fig. 6, which shows the cumulative frequency distribution of the estimates for

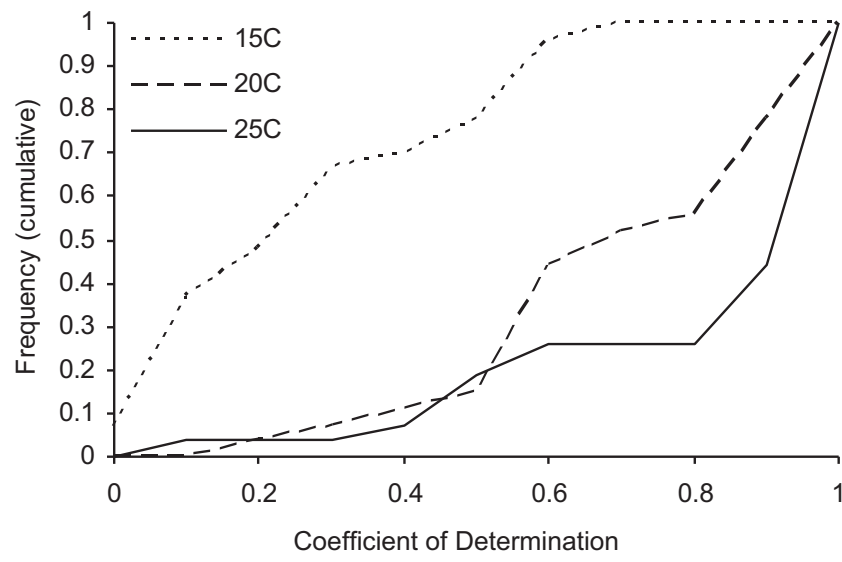

Fig. 4. Cumulative frequency distribution of coefficient of determination, as a function of incubation temperature, using the negative exponential model.

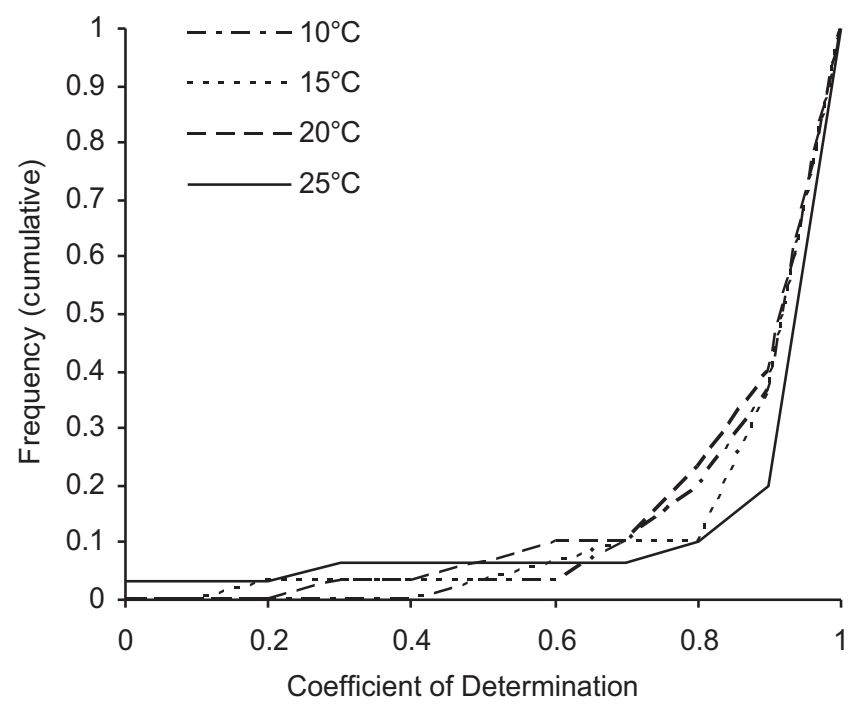

Fig. 5. Cumulative frequency distribution of coefficient of determination, as a function of pre-incubation temperature, using the negative exponential model.

parameter $c$ of the negative exponential model. At $15^{\circ} \mathrm{C}$ (dotted line) the estimate for $c$ was negative for the majority of samples, indicating an asymptotic response. Contrastingly, at $25^{\circ} \mathrm{C}$ (solid line) estimates for $c$ were either close to zero or positive for the majority of the same samples, signifying linear and exponential responses, respectively. At $20^{\circ} \mathrm{C}$ (dashed line), estimates for $c$ were close to zero for over $50 \%$ of the samples (linear response), and either negative (asymptotic response) or positive (exponential response) for the remainder of the samples. The pre-inc temperature did not affect the shape of the $\mathrm{CO}_{2}$ concentration response over time. Fig. 7 demonstrates that estimates for $c$ were either negative or close to zero for most of the samples, irrespective of pre-inc temperature. 


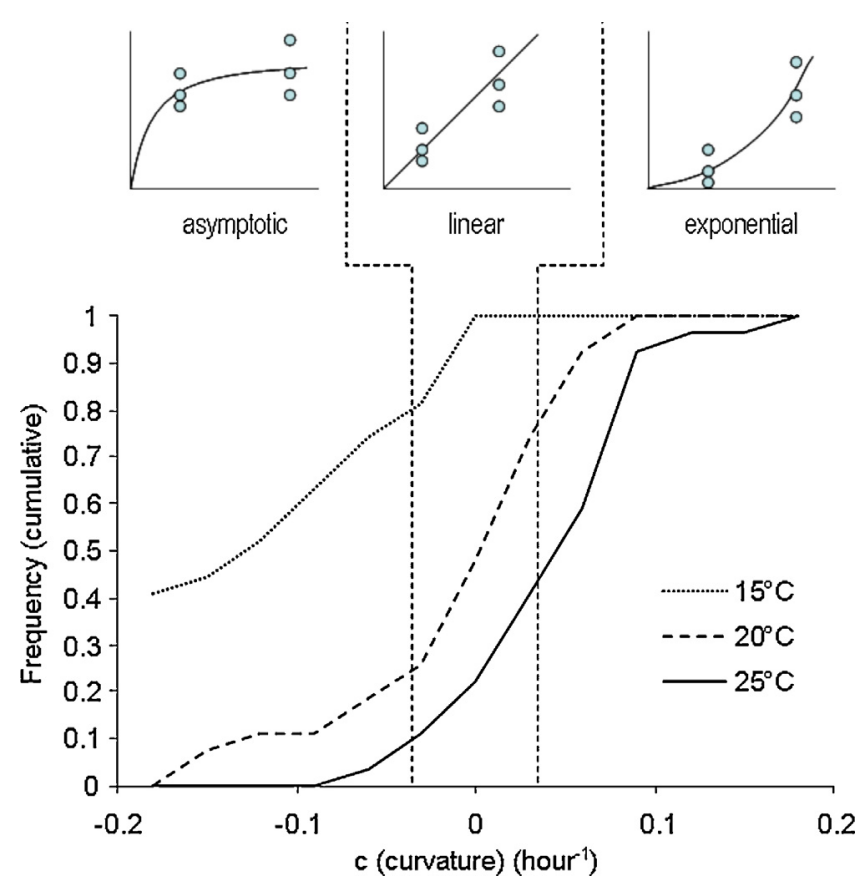

Fig. 6. Cumulative frequency distribution of parameter $c$, as a function of incubation temperature, using the negative exponential model. Parameter $c$ describes the shape of the response of respiration over time.

\subsection{Effect of exp-inc temperature and pre-inc temperature on initial respiration rate}

The flexibility of the negative exponential model in adequately describing a variety of response types, allowed us the use this model to estimate the initial respiration rate $\left(r_{0}\right)$, which, by definition, equates to $-c \cdot \mathrm{CO}_{2 \text {,max }}$. We estimated $r_{0}$ only for model fits that yielded a coefficient of determination of at least 0.50 , in order to eliminate aforementioned erratic responses from further analysis. Figs. 8 and 9 visualise the distribution of $r_{0}$ as a function of temperature. Neither exp-inc temperature (Fig. 8), or pre-inc temperature (Fig. 9), had a consistent affect on the initial respiration rate.

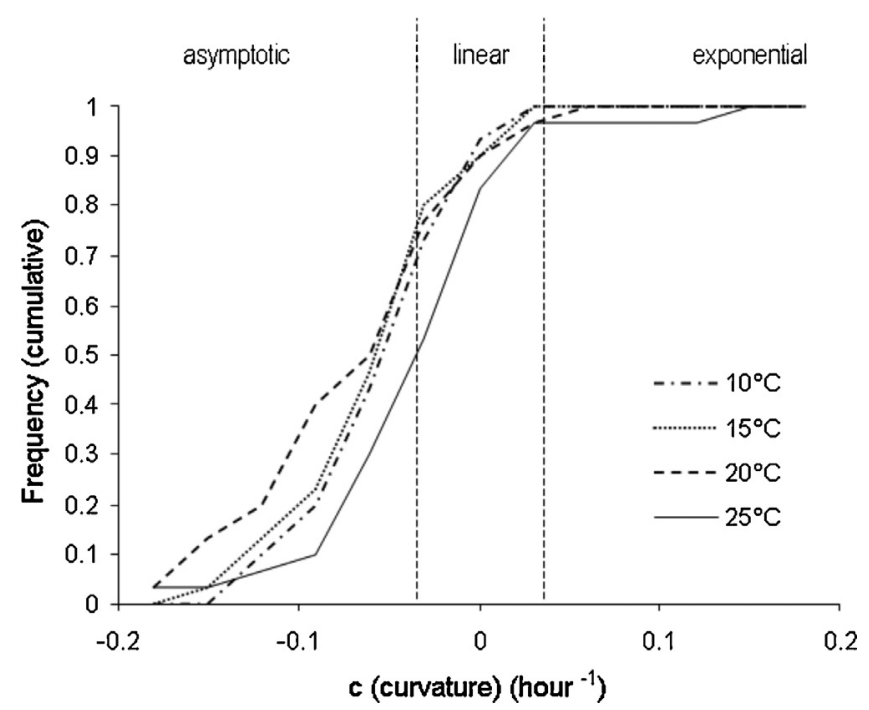

Fig. 7. Cumulative frequency distribution of parameter $c$, as a function of preincubation temperature, using the negative exponential model. Parameter $c$ describes the shape of the response of respiration over time.

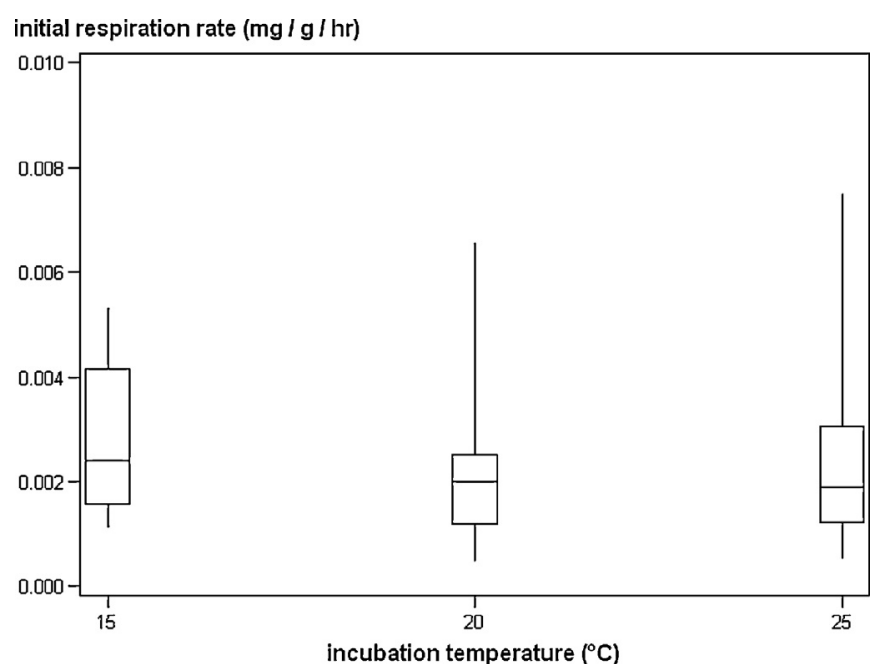

Fig. 8. Initial respiration rate, derived from the negative exponential model, as a function of incubation temperature. Line=median, box =inter-quartile range, whiskers $=95$ percentile range.

\subsection{Relationship between initial respiration rate and average respiration rates}

We used only the data from the pre-inc experiment to test the extent to which the average respiration rate, derived from one temporal measurement, corresponds to the initial respiration rate, as estimated by the model using all temporal measurements over time. Fig. 10 visualises this relationship for estimates of the average respiration rate, measured at time intervals $t=2$ (solid diamonds), $t=6$ (crosses) and $t=24$ (open squares), for each of the incubation temperatures (colours). Most of the open squares $(t=24)$ lie below the line (underestimation of initial response rate), whereas the solid diamonds and crosses both fall closer to the line $(t=2$ and $t=6$ respectively). While the correlation between the logarithmic transformations of the average respiration rate, established at $t=2$ and the initial respiration rate was 0.79 , the average respiration rate at $t=2$, tended to overestimate the initial respiration rate in most cases (note logarithmic scales), resulting in a relatively large root mean square error (RMSE) of $0.00338 \mathrm{mg} \mathrm{g}^{-1} \mathrm{~h}^{-1}$. Large deviations between the average and initial rates of respiration were observed specifically at low rates of respiration. The correlation between the

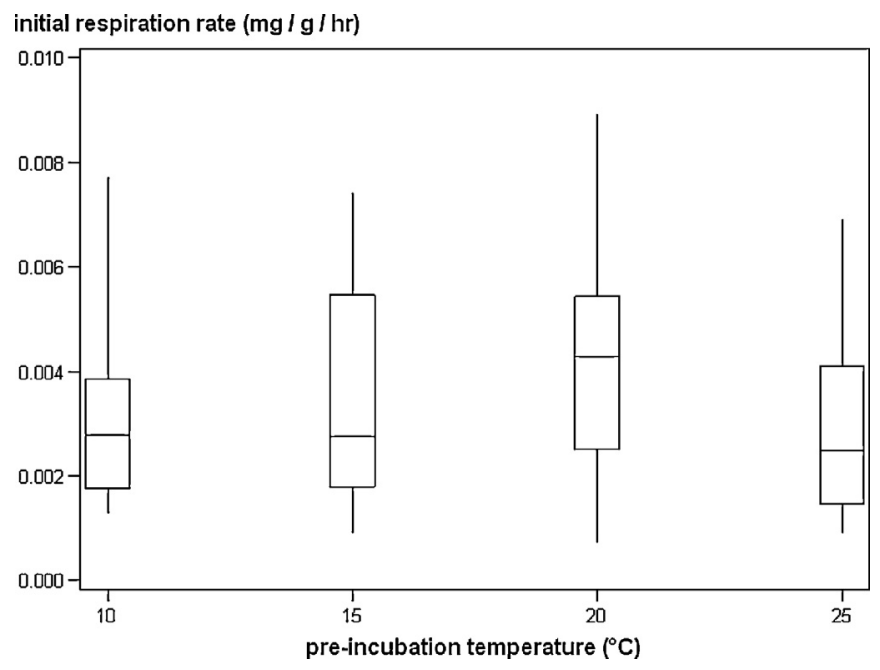

Fig. 9. Initial respiration rate, derived from the negative exponential model, as a function of pre-incubation temperature. Line = median, box = inter-quartile range, whiskers $=95$ percentile range. 


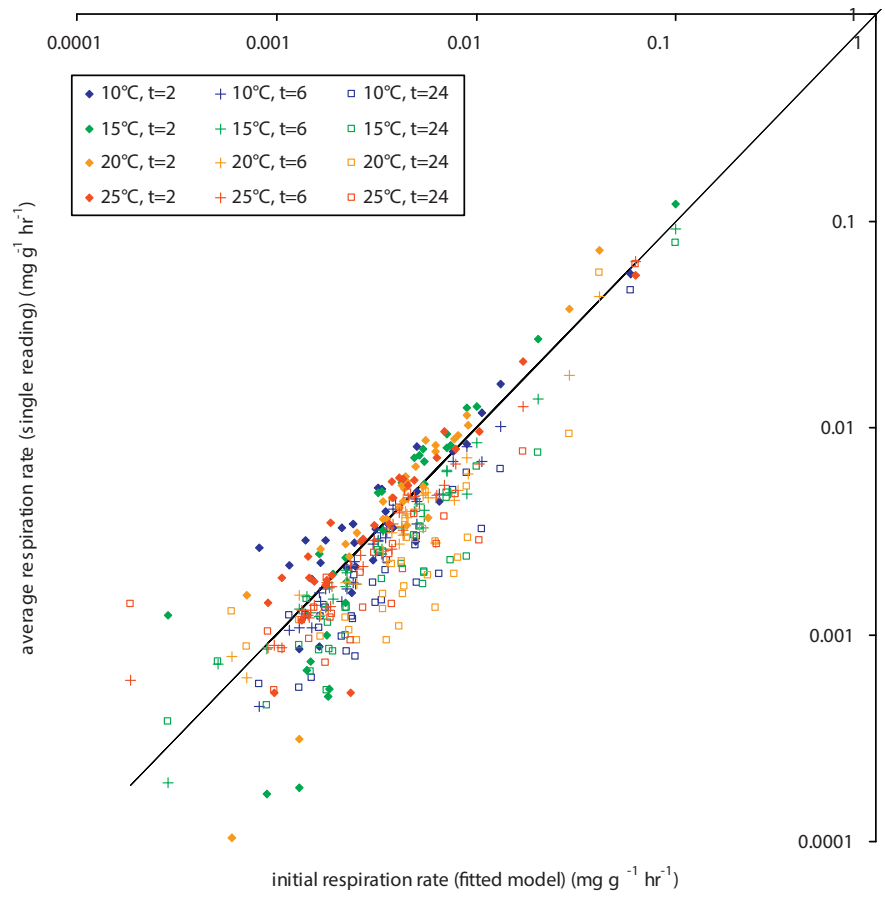

Fig. 10. Relationship between initial respiration rate, derived by fitting the negative exponential model, using all readings, and average respiration rate derived from single readings at $t=2$ (solid diamonds), $t=6$ (crosses) and $t=24$ (open squares) for contrasting pre-incubation temperatures (colours). Note logarithmic scales on both axes.

logarithmic transformations of the average respiration rate, established at $t=6$ and the initial respiration rate was higher and equated to 0.95 , with a lower RMSE of $0.001994 \mathrm{mg} \mathrm{g}^{-1} \mathrm{~h}^{-1}$, although the average respiration rate at this time interval consistently underestimated the initial respiration rate. The average respiration rate measured at $t=24$, gave rise to even larger underestimations of the initial respiration rate, with a weaker logarithmic correlation of 0.75 and higher RMSE of $0.00423 \mathrm{mg} \mathrm{g}^{-1} \mathrm{~h}^{-1}$.

\section{Discussion}

\subsection{Model application}

Descriptive models were used to calculate initial rates of basal respiration due to the non-linear response of $\mathrm{CO}_{2}$ concentrations over the exp-inc period. Of the three models evaluated in this paper, we selected the negative exponential model as the most versatile and robust model to accurately describe the wide variety of observed rates of basal respiration. However, care should be taken in employing the negative exponential model, as its parameters require manual initialisation for the optimisation process, i.e. it requires the data analyst to set arbitrary values for the parameters at the start of the computerised optimisation process. This initialisation should pay particular cognisance to the discontinuity in the value of $\mathrm{CO}_{2 \text {,max }}$ as a function of the value of $c$ : if $c$ is negative, then $\mathrm{CO}_{2 \text {,max }}$ must, by definition, be positive. As $c$ approaches $0, \mathrm{CO}_{2, \max }$ asymptotically approaches infinity for linear responses of the respiration rate, switching to negative values as soon as $c$ exceeds 0 . In practice this means that the $\mathrm{CO}_{2, \max }$ must be correctly initialised by choosing either a positive or negative initialisation value, depending on the shape of the observed respiration response. Where linear responses are observed, this choice can be ambiguous. In such cases we conducted the optimisation process twice, i.e. once with a positive initial value for $\mathrm{CO}_{2, \max }$ and a negative initial value for $c$, and vice versa, and selected the outcome which produced the lowest residual sum of squares.

\subsection{Effect of exp-inc temperature and pre-inc temperature on initial respiration rates}

We did not observe any obvious or consistent effects of either exp-inc temperature or pre-inc temperature on the initial respiration rates (Figs. 8 and 9). This implies that initial respiration rates are not directly impacted by exp-inc or pre-inc temperature. However, exp-inc at $15^{\circ} \mathrm{C}$ gave rise to anomalous respiration responses, and large variation between replicates, for a large number of samples originating throughout the variety of pedo-climatic zones. This research agrees with the recommended protocol of the International Organization for Standardization ISO 16072:2002, which proposes that an experimental incubation temperature should be used within the range of $20-30^{\circ} \mathrm{C}$. Similarly Kirschbaum (1995) reported a temperature sensitivity as expressed by Q10 calculated from a comprehensive literature survey, was far greater at low $<10^{\circ} \mathrm{C}$ compared to moderate to high temperatures of $20-30^{\circ} \mathrm{C}$. Therefore, we do suggest caution at applying temperatures below $20^{\circ} \mathrm{C}$, as this may result in large variation between replicates, when assessing the initial rate of basal respiration. Following the pre-inc recommendations from Jones et al. (2008), this research found no effect of pre-inc temperature on initial rates of basal respiration.

The samples used in this study were derived from a wide variety of pedo-climatic regions across Europe, and displayed an equally wide array of soil properties and land-use types. Nevertheless, we did find a consistent effect of the exp-inc temperature on the shape of the initial respiration response; in other words, on the change in initial respiration rate during the exp-inc period. At lower exp-inc temperatures $\left(15^{\circ} \mathrm{C}\right)$, respiration tended to slow down within the duration of the exp-inc period, giving rise to asymptotic response curves. At an exp-inc temperature of $20^{\circ} \mathrm{C}$ the initial respiration rate tended to remain constant within the $24 \mathrm{~h}$ period, resulting in linear responses, whereas an exp-inc temperature of $25^{\circ} \mathrm{C}$ tended to accelerate the initial rate of respiration within the $24 \mathrm{~h}$ period, leading to exponential responses. It is somewhat surprising that this phenomenon was consistent for the majority of samples, irrespective of their pedo-climatic zone of origin. The mechanism behind the phenomenon is yet unclear: in biology an asymptotic response curve commonly signifies exhaustion of a limited resource, whereas an exponential response commonly indicates either population growth, or additional provision of growth-limiting resources over time (e.g. Schulte et al., 2003). From first principles, we expected higher exp-inc temperatures to lead to more rapid depletion of easily available $C$ resources; hence we expected asymptotic responses to be more prevalent at higher temperatures. In this study however, we found the opposite to be the case. One potential explanation is niche-differentiation within microbial communities in relation to temperatures, with heat-tolerant communities having access to larger quantities of substrate resources, this may be reflected by the time of year that samples were taken, in this case June. Alternatively, it is conceivable that the shapes of the curves reflect the differences between the pre-inc temperature and the exp-inc temperatures. During the experimental incubation experiment all treatments were preincubated at $20^{\circ} \mathrm{C}$, therefore the asymptotic response at exp-inc temperatures of $15^{\circ} \mathrm{C}$ could merely reflect the "slowing down" of the respiration rate while the sample cools down from $20^{\circ} \mathrm{C}$ to $15^{\circ} \mathrm{C}$ during incubation, while, symmetrically, the exponential response at exp-inc temperatures of $25^{\circ} \mathrm{C}$ would merely reflect the acceleration of the respiration rate while the sample heats up from $20^{\circ} \mathrm{C}$ to $25^{\circ} \mathrm{C}$. Hamdi et al. (2011) reported a similar heating effect causing an increase in the soil respiration rate over time in a similar study looking at the impact of pre-incubation (basal) 
temperatures of 20 to $50{ }^{\circ} \mathrm{C}$ on soil sampled at an experimental research station in North-west Tunisia. In experiments for the assessment of initial basal respiration, such artefacts arising from samples "cooling down" and "heating up" during the incubation could be negated by applying identical pre-inc and exp-inc temperatures.

\subsection{Optimum duration of incubation}

In this study, we measured $\mathrm{CO}_{2}$ concentration at multiple intervals during the exp-inc period. This enabled us to reliably estimate the initial respiration rate and detect temporal changes in initial respiration rate throughout the exp-inc period. However, multiple measurements of $\mathrm{CO}_{2}$ concentration are often associated with challenges in terms of logistics and resource requirements, in particular in monitoring applications and large scale experiments. In this paper, we demonstrated that, even in such cases, there is significant merit in temporal measurements to model the shape of the curve of the initial response rate. Nevertheless, in this paper we also showed that, where resources or logistical arrangements are limiting, the initial respiration rate can be satisfactorily estimated from the average respiration rate, measured at a single point in time. However, in this case, length of the exp-inc period, (the time interval of $\mathrm{CO}_{2}$ concentration measurement), is pivotal for the accuracy of this estimation. Our data, based on samples from 27 sites from contrasting pedo-climatic regions across Europe, shows that the initial respiration rates, calculated from average respiration rates from measurements at T24, will significantly underestimate the response. The initial respiration rates calculated from average respiration rates measured after 2 and $6 \mathrm{~h}$ slightly overestimated and underestimated the response respectively, with the $6 \mathrm{~h}$ measurement giving the lowest root mean square error.

This suggests that, for the purpose of a single point estimation of the initial respiration rate, the optimum length of the incubation period is likely to be between 4 and $6 \mathrm{~h}$. This agrees with the findings of Campbell et al. (2003), who suggested an experimental incubation period of $6 \mathrm{~h}$ when assessing multiple substrate induced respiration (which includes a basal measurement); this has since been applied by numerous studies for basal respiration (e.g. Bundy et al., 2004 and Vanhala et al., 2005).

\section{Conclusions}

We have demonstrated in this study that the measurement of initial rate of basal soil respiration is most consistent at an experimental incubation temperature of $20^{\circ} \mathrm{C}$ and $25^{\circ} \mathrm{C}$, with large variation between sample replicates found at $15^{\circ} \mathrm{C}$. This is consistent with the recommendations of ISO 16072:2002. However, we do see a change in the shape of the initial respiration curve with differing exp-inc temperatures, suggesting a possible shift in the microbial community. This study found that the time interval/temperature combinations recommended for pre-incubation of soils prior to soil basal respiration have no effect on initial respiration rates, though it may be prudent to equalise the pre-inc temperature to the exp-inc temperature to avoid the cooling down or heating up of the sample during the exp-inc period. Finally, if only a single point estimation of the initial respiration rate can be measured, the optimum length of the exp-inc period is between 4 and $6 \mathrm{~h}$.

\section{Acknowledgements}

The ENVironmental ASsessment of Soil for mOnitoring (ENVASSO) Project, funded as Scientific Support to Policy (SSP) under the European Commission 6th Framework Programme (Contract 022713, 2006-8).

\section{References}

Anderson, J.P.E., Domsch, K.H., 1977. A physiological method for the quantitative measurement of microbial biomass in soils. Soil Biol. Biochem. 10, 215-221.

Bárcenas-Moreno, G., García-Orenes, F., Mataix-Solera, J., Mataix-Beneyto, J., Bååth, E., 2011. Soil microbial recolonisation after a fire in a Mediterranean forest. Biol. Fertil. Soils 47, 261-272.

Bispo, A., Cluzeau, D., Creamer, R., Dombos, M., Graefe, U., Krogh, P.H., Sousa, J.P., Peres, G., Rutgers, M., Winding, A., Römbke, J., 2009. Indicators for monitoring soil biodiversity. Integr. Environ. Assess. Manag. 5, 717-719.

Bloem, J., Schouten, A.J., Sørensen, S.J., Rutgers, M., Van der Werf, A., Breure, A.M., 2006. Monitoring and evaluating soil quality. In: Bloem, J., Benedetti, A., Hopkins, D.W. (Eds.), Microbiological Methods for Assessing Soil Quality. CAB International, Wallingford, Oxfordshire, UK, pp. 23-49.

Bundy, J., Paton, G.I., Campbell, C.D., 2004. Combined microbial community level and single species biosensor responses to monitor recovery of oil polluted soil. Soil Biol. Biochem. 36, 1149-1159.

Campbell, C.D., Chapman, S.J., Cameron, C.M., Davidson, M.S., Potts, J.M., 2003. A rapid microtiter plate method to measure carbon dioxide evolved from carbon substrate amendments so as to determine the physiological profiles of soil microbial communities by using whole soil. Appl. Environ. Microbiol. 69, 3593-3599.

Cĕrnohlávková, J., Jarkovský, J., Nešporová, M., Hofman, J., 2009. Variability of soil microbial properties: effects of sampling, handling and storage. Ecotoxicol. Environ. Saf. 72, 2102-2108.

Creamer, R.E., Bellamy, P., Black, H.I.J., Cameron, C.M., Campbell, C.D., Chamberlain, P., Harris, J., Parekh, N., Pawlett, M., Poskitt, J., Stone, D., Ritz, K., 2009. An inter-laboratory comparison of multi-enzyme and multiple substrate-induced respiration assays to assess method consistency in soil monitoring. Biol. Fertil. Soils 45, 623-633.

Dilly, O., Zyakun, A., 2008. Priming effect and respiratory quotient in a forest soil ammended with glucose. Geomicrobiol. J. 25, 425-431.

European Environment Agency, 2002. Biogeographical Regions of Europe 2001. <http://www.eea.europa.eu/data-and-maps/figures/biogeographical-regionseurope-2001/> (Last accessed August, 2013).

Fernandes, S.A.P., Bettiol, W., Cerri, C.C., 2005. Effect of sewage sludge on microbial biomass, basal respiration, metabolic quotient and soil enzymatic activity. Appl. Soil Ecol. 30, 65-77.

Fließbach, A., Hans-Rudolf, O., Lucie, G., Mäder, P., 2007. Soil organic matter and biological soil quality indicators after 21 years of organic and conventional farming. Agric. Ecosyst. Environ. 118, 273-284.

Francaviglia, R., 2008. Agricultural Soil Erosion and Soil Biodiversity: Developing Indicators for Policy Analyses. OECD, Paris.

Gömöryová, E., Sťrelcová, K., Fleischer, P., Gömöry, D., 2011. Soil microbial characteristics at the monitoring plots on windthrow areas of the Tatra National Park (Slovakia): their assessment as environmental indicators. Environ. Monit. Assess. 174, 31-45.

Grayston, S.J., Griffith, G.S., Mawdsley, J.L., Campbell, C.D., Bardgett, C.D., 2001 Accounting for variability in soil microbial communities of temperate upland grassland ecosystems. Soil Biol. Biochem. 33, 533-551.

Hamdi, S., Chevallier, T., Aissa, N.B., Hammouda, M.B., Gallali, T., Chotte, J., Bernoux, M., 2011. Short-term temperature dependence of heterotrophic soil respiration after one month of pre-incubation at different temperatures. Soil Biol. Biochem. 43, 1752-1758.

Hofman, J., Dušek, L., Klánová, J., Bezchlebová, J., Holoubek, I., 2004. Monitoring microbial biomass and respiration in different soils from the Czech Republic - a summary of results. Environ. Int. 30, 19-30.

ISO 10381-6, 1993a. Soil quality - sampling: Part 6. Guidance on the collection, handling and storage of soil for the assessment of aerobic microbial processes in the laboratory. International Organization for Standardization. Geneva, Switzerland.

ISO $11465,1993 \mathrm{~b}$. Soil quality - determination of dry matter and water content on a mass basis - gravimetric method. International Organization for Standardization. Geneva, Switzerland.

ISO 16072, 2002. Soil quality - laboratory methods for determination of microbial soil respiration. International Organization for Standardization. Geneva, Switzerland.

Jenkinson, D.S., Powlson, D.S., 1976. Effects of Biocidal Treatments on Metabolism in Soil. 5. Method for Measuring Soil Biomass. Soil Biology \& Biochemistry 8, 209-213.

Jones, R.J.A., Verheijen, F.G.A., Reuter, H.I., Jones, A.R., 2008. Environmental Assessment of Soil for Monitoring, Vol. V: Procedures \& Protocols. EUR 23490 EN/5, Office for the Official Publications of the European Communities, Luxembourg, pp. 165.

Kirschbaum, M.U., 1995. The temperature dependence of soil organic matter decomposition, and the effect of global warming on soil organic C storage. Soil Biol. Biochem. 27 (6), 753-760.

Maassen, S., Wirth, S., 2004. Soil microbiological monitoring of a pine forest after partial thinning for stand regeneration with beech seedlings. Soil Sci. Plant Nutr. 50, 815-819. 
Mulder, C., Cohen, J.E., Setälä, H., Bloem, J., Breure, A.M., 2005. Bacterial traits, organism mass and numerical abundance in the detrital soil food web of Dutch agricultural grasslands. Ecol. Lett. 8, 80-90.

Pell, M., Stenström, J., Granhall, U., 2006. Soil Respiration. In: Bloem, J., Hopkins, D.W., Benedetti, A. (Eds.), Microbial Methods for Assessing Soil Quality. CAB International, Wallingford, Oxfordshire, U.K..

Ritz, K., Wheatley, R.E., 1989. Effects of water amendment on basal and substrateinduced respiration rates of mineral soils. Biol. Fertil. Soils 8, 242-246.

Ritz, K., Harris, J.A., Pawlett, M., Stone, D., 2006. Using Science to Create a Better Place: Catabolic Profiles as an Indicator of Soil Microbial Functional Diversity. Environment Agency Science Report SC040063/SR

Rousk, J., Brookes, P.C., Bååth, E., 2009. Contrasting soil pH effects on fungal and bacterial growth suggest functional redundancy in carbon mineralization. Appl. Environ. Microbiol. 75, 1589-1596.
Schulte, R.P.O., Lantinga, E.A., Struik, P.C., 2003. Analysis of the production stability of mixed grasslands I: a framework for the qualification of production stability in grassland ecosystems. Ecol. Modell. 159, 43-69.

Star Chromatography Workstation, 2004. Version 6.41, Copyright (18989-2004) Varian Inc.

Uzun, N., Uyanoz, R., 2011. Determination of urease catalase activities and $\mathrm{CO}_{2}$ respiration in different soils obtained from in semi arid region Konya, Turkey. Trends Soil Plant Sci. J. 2, 1-6.

Vanhala, P., Tamminen, P., Fritze, H., 2005. Relationship between basal soil respiration rate, tree stand and soil characteristics in boreal forests. Environ. Monit. Assess. 101, 85-92.

Winding, A., Hund-Rink, K., Rutgers, M., 2005. The use of microorganisms in ecological soil classification and assessment concepts. Ecotoxicol. Environ. Saf. 62 230-248. 